\title{
Enantiomeric Separation and Determination of Stereospecific Drug Release from Marketed Racemic Amlodipine Besylate Tablets by HPLC
} JaganMohan Somagoni ${ }^{1,2}$, Sunil Reddy ${ }^{1}$, Someshwar Koorelli1 ${ }^{1}$, Sarangapani Manda ${ }^{2}$ and Madhusudan Rao Yamsani ${ }^{*}$

${ }^{1}$ Centre for Biopharmaceutics and Pharmacokinetics, University College of Pharmaceutical Sciences, Kakatiya University, Warangal - 506009 (A.P.) India ${ }^{2}$ Department of Medicinal Chemistry, University College of Pharmaceutical Sciences, Kakatiya University, Warangal - 506009 (A.P.) India

\begin{abstract}
The objective of carrying out this research work was to investigate the effect of chirality on the stereospecific dissolution of amlodipine from various marketed racemic amlodipine besylate tablets. Amlodipine is a calcium ion influx inhibitor which is used in the treatment of hypertension and angina.

In this study dissolution of various marketed tablets was performed using USP type II apparatus in $0.1 \mathrm{~N} \mathrm{HCI}$ at $75 \mathrm{rpm}$ with temperature being maintained at $37 \pm 0.5^{\circ} \mathrm{C}$. Chromatographic separation of amlodipine enantiomers was performed using HPLC equipped with UV-Visible detector using Chiral AGP column (100 x $4.6 \mathrm{~mm}$ I.D., $5 \mu$ particle size). There was no significant difference between the cumulative drug release profiles of $S$ and $R$ enantiomers $(p>0.05)$ in 16 out of 20 marketed racemic amlodipine besylate tablets except for amlong, stamlo-5, amlopin-5 and amcard $(p<0.05)$. Though the stereospecificity in the dissolution was found with the four brands i.e., amlong, stamlo-5, amlopin-5 and amcard, the stereospecificity found with Stamlo- 5 was quite opposite to the stereospecificity of amlong, amlopin-5 and amcard because the dissolution of R enantiomer of amlong, amlopin- 5 and amcard was significantly more compared to their $\mathrm{S}$ enantiomer where as in the case of stamlo- 5 the dissolution of $\mathrm{S}$ enantiomer was more compared to its $\mathrm{R}$ enantiomer.
\end{abstract}

Keywords: Chirality; stereospecificity; Amlodipine; Enantiomers; Chiral separation

\section{Introduction}

Drug chirality is now a major theme in the design, discovery, development, launching and marketing of new drugs [1,2]. Stereochemistry is an essential dimension in pharmacology. In past decades the pharmacopoeia was dominated by racemates, but since the emergence of new technologies in the 1980s that allowed the preparation of pure enantiomers in significant quantities, the awareness and interest in the stereochemistry of drug action has increased.

This interest can be attributed largely to a heightened awareness that enantiomers of a racemic drug may have different pharmacological activities, as well as different pharmacokinetic and pharmacodynamic effects [3-5]. The body being amazingly chiral selective, will interact with each racemic drug differently and metabolize each enantiomer by a separate pathway to produce different pharmacological activity. Thus, one isomer may produce the desired therapeutic activities, while the other may be inactive or, in worst cases, produce unwanted effects $[6,7]$.

Over the last ten to fifteen years drug chirality, particularly the use of single enantiomers versus racemic mixtures has become an area of considerable interest. In addition to new chemical entities a number of old racemates have been re-evaluated as potential single enantiomer products with the possibility for an improved therapeutic profile. These so-called "chiral switches" have resulted in a number of agents being commercially available as both single enantiomer and racemic mixtures at the same time.

In principle, any of the following properties could render a single enantiomer preferable [8]:

» The single form has fewer adverse effects

» The desired action of the active form is interfered with by the inactive form

\section{» One form is more prone to adverse drug interactions}

Many familiar drugs were introduced to the market as single enantiomers, e.g. Amlodipine, Omeprazole. However, when the patent of a successful racemic drug nears expiry, it can be remarketed as a single enantiomer under a new patent [9].

It is very important to distinguish the single enantiomer drug from the racemic form because they may differ in their dosages, efficacies, side effect profiles or even indicated use. The two enantiomers of a chiral drug may also differ significantly in their bioavailability, rate of metabolism, metabolites, excretion, potency, receptor selectivity and toxicity. The use of single-enantiomer drugs can potentially lead to simpler and more selective pharmacologic profiles, improved therapeutic indices, and decreased side effects.

S(-) Amlodipine is a widely prescribed calcium channel blocking (CCB) antihypertensive agent. However, amlodipine is a racemate with an equal proportion of two enantiomers " $S$ " and " $R$ ", thus patients receiving amlodipine are in fact taking two different drugs $\mathrm{S}$-Amlodipine and R-Amlodipine which do not have the same level of antagonistic effect on the calcium channel receptor. The S-enantiomer of amlodipine is active and the R-enantiomer is inactive in terms of calcium channel blocking activity.

*Corresponding author: Prof. (Dr.) Y. Madhusudan Rao, Centre for Biopharmaceutics and Pharmacokinetics, University College of Pharmaceutical Sciences, Kakatiya University, Warangal - 506 009. (A.P.), INDIA. Tel: +91-8702438844; Fax: +91-870-2570543; E-mail: yamsani123@gmail.com

Received June 18, 2011; Accepted July 09, 2011; Published July 11, 2011

Citation: Somagoni J, Reddy S, Koorelli S, Manda S, Yamsani MR (2011) Enantiomeric Separation and Determination of Stereospecific Drug Release from Marketed Racemic Amlodipine Besylate Tablets by HPLC. Pharm Anal Acta 2:129. doi:10.4172/2153-2435.1000129

Copyright: (C) 2011 Somagoni J, et al. This is an open-access article distributed under the terms of the Creative Commons Attribution License, which permits unrestricted use, distribution, and reproduction in any medium, provided the original author and source are credited. 
S(-)Amlodipine has 1000 fold stronger calcium channel blocking activity than R- amlodipine. S(-)Amlodipine is therefore responsible for all of the CCB-mediated pharmacodynamic action of amlodipine including its anti-anginal activity without the concomitant liability of adverse effects associated with the racemic mixture of amlodipine.

In case where the racemic drugs with chirality are prepared it is the responsibility of a pharmaceutical scientist to select suitable chiral excipients so that active enantiomer releases first to give the therapeutic benefit to the patient.

The FDA regulatory guidelines do have a major impact on arrival of new chemical entities into the market resulting in the dramatic decline in the development of racemates in recent years. The available data for 15 FDA approved drugs in the period January-August 2003 indicate $64 \%$ single enantiomers, $14 \%$ racemates and $22 \%$ achirals. In spite of the absence of any FDA-approved racemates in 2001 and only two approved racemates in 2002 (worldwide), racemic drugs should not be declared as a dead option. It remains to be seen whether or not racemates will disappear from the drug approval scene $[10,11]$.

\section{Experimental}

\section{Materials}

Twenty brands of racemic amlodipine besylate tablets of which ten brands were $10 \mathrm{mg}$ and other ten brands were $5 \mathrm{mg}$ purchased from different retail outlets in Andhra Pradesh, India. All the products were manufactured within six months from the date of the study.

\section{Dissolution study}

Dissolution of all the tablets was done using USP type II apparatus (LABINDIA Model: DS 8000) in $0.1 \mathrm{~N} \mathrm{HCl}$ at $75 \mathrm{rpm}$ with temperature being maintained at $37 \pm 0.5^{\circ} \mathrm{C}$. Samples were withdrawn at $15,30,45$ and 60 minute time points and were analyzed for dissolved amlodipine using chiral AGP column at $235 \mathrm{~nm}$. The dissolution experiments were done in triplicate.

\section{Chromatographic apparatus and conditions}

Chromatographic chiral separation of amlodipine enantiomers was performed on a Shimadzu HPLC System (Japan) equipped with UV-Visible detector using Chiral AGP column (100 x 4.6 mm I.D., $5 \mu$ particle size). The wavelength for UV detection was set at 235 $\mathrm{nm}$. The mobile phase was $10 \mathrm{mM}$ Ammonium acetate buffer with $1 \%$ 1-Propanol adjusted to $\mathrm{pH} 4.6$ at a flow rate of $0.9 \mathrm{ml} \mathrm{min}^{-1}$ with an injector valve fitted to a $50 \mu \mathrm{l}$ volume sample loop. The retention times for $\mathrm{R}$ and $\mathrm{S}$ enantiomers of amlodipine were 5 and 7 minutes respectively (Figure 1).

\section{Statistical analysis}

To know whether the enantiospecific dissolution is significant or not the dissolution profiles of all the brands were tested using a oneway analysis of variance (ANOVA) or unpaired t test. If the significant differences exist when ANOVA was used, the pair wise comparison of enantiomers was done for all the brands to find out statistical significant difference using a Dunnet's test. When the normality test failed, Kruskal-Wallis one-way ANOVA was used to find out if the significant differences exist between different systems. The statistical analysis was conducted using SigmaStat software version 1.0 (Jandel Corp., California). The difference in the sample means were considered to be significant at $\mathrm{p}<0.05$.

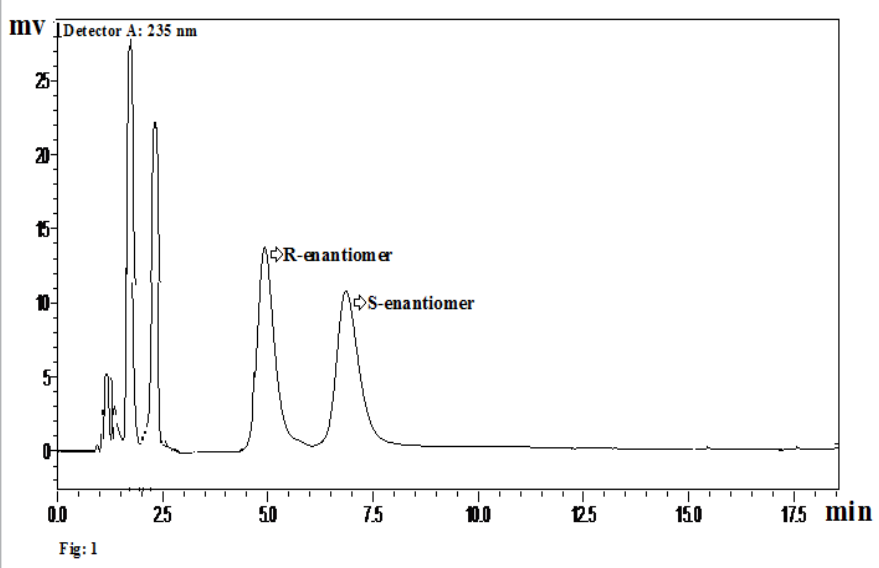

Figure 1: Chromatogram showing the chiral separation of amlodipine enantiomers.

\section{Results and Discussion}

\section{Investigation for stereospecific dissolution}

Dissolution tests were conducted for twenty brands of racemic amlodipine besylate tablets (Table 1 ) of which ten brands were $10 \mathrm{mg}$ dose (A-J) and other ten brands were $5 \mathrm{mg}$ dose (K-T).

The United States Pharmacopoeia stipulates that at 30 minute dissolution time point, all tablets should have released into the dissolution medium an amount not less than $60 \%$ of the labelled amount of amlodipine besylate.

From the dissolution of racemic amlodipine besylate tablets of 10 mg dose (A-J) it was observed that there was a not less than $70 \%$ of drug release of both $\mathrm{S}$ and $\mathrm{R}$ enantiomers at 30 minute dissolution time point from all the brands except amlong. Hence all the brands (A-T) were passing the dissolution test as per U.S.P [12].

In case of racemic amlodipine besylate tablets of $10 \mathrm{mg}$ dose (AJ: Figure 2 (included as supplementary data)) there was no significant difference between the cumulative drug release profiles of $S$ and $R$ enantiomers $(p>0.05)$ except for amlong. In case of amlong there was a significant difference in the dissolution of $S$ and $R$ enantiomers up to 30 minutes $(\mathrm{p}<0.05)$. The dissolution of $\mathrm{R}$ enantiomer of amlong was significantly more compared to its $\mathrm{S}$ enantiomer up to 30 minutes after which the enantiospecific dissolution was lost. Hence the release of amlodipine enantiomers from all the brands of racemic amlodipine besylate tablets of $10 \mathrm{mg}$ dose was non-enantioselective except amlong.

In case of racemic amlodipine besylate tablets of $5 \mathrm{mg}$ dose (KT: Figure 3 (included as supplementary data)) there was no significant difference between the cumulative drug release profiles of $\mathrm{S}$ and $\mathrm{R}$ enantiomers $(p>0.05)$ except for stamlo-5, amlopin-5 and amcard. Significant stereospecific difference in the dissolution of $\mathrm{S}$ and $\mathrm{R}$ enantiomers was found with brands stamlo-5, amlopin-5 up to 30 minutes where as in case of amcard this stereospecificity was found only up to 15 minutes. The dissolution of $\mathrm{R}$ enantiomer of amlopin-5 and amcard was significantly more compared to its $\mathrm{S}$ enantiomer up to 30 minutes and 15 minutes respectively and after which the enantiospecific dissolution was lost. But surprisingly in case of stamlo-5, the dissolution of $\mathrm{S}$ enantiomer was significantly more when compared to its $\mathrm{R}$ enantiomer up to 30 minutes. Though the stereospecificity in 
Citation: Somagoni J, Reddy S, Koorelli S, Manda S, Yamsani MR (2011) Enantiomeric Separation and Determination of Stereospecific Drug Release from Marketed Racemic Amlodipine Besylate Tablets by HPLC. Pharm Anal Acta 2:129. doi:10.4172/2153-2435.1000129

Page 3 of 4

\begin{tabular}{|c|c|c|c|c|c|}
\hline S.No & Brand name & Code & Dose & Batch No & Company \\
\hline 1 & AMLOGARD & A & $10 \mathrm{mg}$ & $920-05102$ & Pfizer Ltd. \\
\hline 2 & AMTAS-10 & B & $10 \mathrm{mg}$ & DK2265 & INTAS Pharmacuticals \\
\hline 3 & STAMLO-10 & C & $10 \mathrm{mg}$ & 000123 & Dr.Reddy's Laboratories \\
\hline 4 & AMLODAC-10 & D & $10 \mathrm{mg}$ & ZH1532 & ZYDUS HEALTH CARE \\
\hline 5 & AMLOZ-10 & $E$ & $10 \mathrm{mg}$ & 431102 & SHREYA LIFE SCIENCES \\
\hline 6 & PRIMODIL-10 & $\mathrm{F}$ & $10 \mathrm{mg}$ & 80343 & Medley Pharmaceuticals \\
\hline 7 & AMLOPRES-10 & G & $10 \mathrm{mg}$ & D84511 & CIPLA pharmaceuticals \\
\hline 8 & AMCHEK & $\mathrm{H}$ & $10 \mathrm{mg}$ & AV1D9M & Indoco remedies Ltd. \\
\hline 9 & CORVADIL & 1 & $10 \mathrm{mg}$ & $\mathrm{BCOH} 09003$ & Unichem Laboratories Ltd \\
\hline 10 & AMLONG-10 & $J$ & $10 \mathrm{mg}$ & AMCD0006 & Microlabs \\
\hline 11 & STAMLO-5 & K & $5 \mathrm{mg}$ & 000123 & Dr.Reddys Laboratories \\
\hline 12 & AMLOPIN & L & $5 \mathrm{mg}$ & 28002924 & USv \\
\hline 13 & AMCARD-5 & M & $5 \mathrm{mg}$ & AY261009 & Ontop pharmaceuticals \\
\hline 14 & AMLIQ & N & $5 \mathrm{mg}$ & 801 & $\mathrm{~A} 1$ \\
\hline 15 & AMLOVAS-5 & $\mathrm{O}$ & $5 \mathrm{mg}$ & BAB914 & Macleods \\
\hline 16 & AMLO-5 & $P$ & $5 \mathrm{mg}$ & OR9AR012 & Windlas biotech limited \\
\hline 17 & AMLOKATH-5 & Q & $5 \mathrm{mg}$ & T062H9 & Lifemedicare \\
\hline 18 & AMLOKIND-5 & $\mathrm{R}$ & $5 \mathrm{mg}$ & 09AD266 & Mankind \\
\hline 19 & AMODEP & S & $5 \mathrm{mg}$ & AFT9111 & FDC limited \\
\hline 20 & AMLOSTAT-5 & $\mathrm{T}$ & $5 \mathrm{mg}$ & VA295010 & Biochem pharma Industries Ltd \\
\hline
\end{tabular}

Table 1: Marketed racemic amlodipine besylate tablets for which stereospecific dissolution was investigated using Chiral HPLC.

\begin{tabular}{|c|c|c|c|c|c|c|c|c|c|c|}
\hline \multicolumn{11}{|c|}{ S/R Ratios of racemic amlodipine besylate $10 \mathrm{mg}$ tablets } \\
\hline Time (min) & $A$ & $\mathrm{~B}$ & $\mathrm{C}$ & $\mathrm{D}$ & $\mathrm{E}$ & $\mathrm{F}$ & G & $\mathrm{H}$ & I & $\mathbf{J}$ \\
\hline 15 & 1.01 & 0.96 & 1.01 & 1.01 & 0.98 & 0.95 & 0.96 & 1.02 & 1.03 & 0.71 \\
\hline 30 & 1.07 & 0.92 & 1.04 & 0.92 & 1.15 & 0.98 & 1.02 & 1.03 & 1.1 & 0.77 \\
\hline 45 & 1.03 & 1 & 1.05 & 0.97 & 1.03 & 1.01 & 0.94 & 1.02 & 1.05 & 0.92 \\
\hline 60 & 0.98 & 0.74 & 1.01 & 1 & 1.14 & 1 & 1.05 & 0.99 & 1.02 & 1 \\
\hline \multicolumn{11}{|c|}{$\mathrm{S} / \mathrm{R}$ Ratios of racemic amlodipine besylate $5 \mathrm{mg}$ tablets } \\
\hline Time $(\min )$ & $\mathbf{K}$ & $\mathbf{L}$ & M & $\mathrm{N}$ & $\mathrm{O}$ & $\mathrm{P}$ & Q & $\mathrm{R}$ & S & $\mathrm{T}$ \\
\hline 15 & 1.23 & 0.81 & 0.85 & 0.93 & 1.01 & 0.99 & 0.97 & 1 & 0.99 & 1.03 \\
\hline 30 & 1.18 & 0.83 & 0.99 & 0.95 & 1.02 & 1.04 & 1.03 & 1.04 & 0.97 & 1.06 \\
\hline 45 & 0.92 & 1 & 1.2 & 0.98 & 0.95 & 1.08 & 1.07 & 0.98 & 0.96 & 1.01 \\
\hline 60 & 0.94 & 1.06 & 1.07 & 0.96 & 1.03 & 0.94 & 0.99 & 1.04 & 1.05 & 0.95 \\
\hline
\end{tabular}

Note: symbols are as mentioned in the table 1.

Table 2: S/R Ratios of marketed racemic amlodipine besylate tablets.

the dissolution was found with the four brands i.e., amlong, stamlo-5, amlopin-5 and amcard, the stereospecificity found with Stamlo-5 was quite opposite to the stereospecificity of amlong, amlopin- 5 and amcard (Figure 4 (included as supplementary data)).

Though the brands Stamlo-5 and Stamlo-10 belong to same company and the difference is only the dose, the stereospecific drug release was found only with stamlo- 5 but not with stamlo- 10 .

The reason for this may be because of the difference in the excipients used with these two brands or stereospecificity here might be dose dependent which exists at lower dose and vanishes at higher dose. As the stamlo- 5 and stamlo- 10 are the marketed products we do not know the components of formulations. Hence it is very difficult to authors to give exact reason for the difference shown by stamlo- 5 and stamlo- 10 .

\section{Interpretation of $S / R$ values}

As S-Amlodipine is more active than the R-enantiomer, the faster release of S-enantiomer from a dosage form is very essential to treat the emergency conditions like hypertension and angina. Marketed products showing $\mathrm{S} / \mathrm{R}$ ratio less than one are said to be releasing the R-enantiomer (Inactive form) faster than the S-enantiomer (Active form) where as the marketed products showing $S / R$ ratio more than one are said to be releasing the $\mathrm{S}$-enantiomer faster than the R-enantiomer. If the $\mathrm{S} / \mathrm{R}$ ratio is either one or close to one, it means that the product is releasing both the enantiomers at equal rate.

Therefore in this study $\mathrm{S} / \mathrm{R}$ ratios of all the twenty racemic brands were calculated to see the presence of stereospecific dissolution of enantiomers. From the Table 2 it was clear that $S / R$ ratios of all the racemic brands was close to one except with four brands which are 
Citation: Somagoni J, Reddy S, Koorelli S, Manda S, Yamsani MR (2011) Enantiomeric Separation and Determination of Stereospecific Drug Release from Marketed Racemic Amlodipine Besylate Tablets by HPLC. Pharm Anal Acta 2:129. doi:10.4172/2153-2435.1000129

Page 4 of 4

amlong, stamlo-5, amlopin-5 and amcard. In amlong and amlopin-5 $\mathrm{S} / \mathrm{R}$ ratios were less than one up to 30 minute dissolution time point whereas in the case of amcard the S/R ratio was less than one only up to 15 minute dissolution time point indicating the better stereospecific dissolution of R-enantiomer (Inactive form) up to 30 minutes in amlong and amlopin-5 whereas up to 15 minutes in amcard. S/R value was more than one up to 30 minute dissolution time point in stamlo-5 indicating the better stereospecific dissolution of S-enantiomer (Active form) up to 30 minutes.

\section{Statistical analysis}

Though the dissolution profiles of all the brands were seemed to be following stereospecificity, when the data was subjected to a statistical treatment it was found that the difference in the dissolution of $S$ and $\mathrm{R}$ enantiomers was significant only in the case of amlong, stamlo-5, amlopin-5 and amcard brands $(\mathrm{p}<0.05)$.

\section{Conclusion}

From the dissolution profiles, $\mathrm{S} / \mathrm{R}$ values and with the statistical treatment of this data of marketed racemic amlodipine besylate tablets it was concluded that there was a significant stereospecific dissolution with amlong, stamlo-5, amlopin-5 and amcard and no stereospecificity was observed with the remaining brands. It is, however, to be verified whether these small differences in the release rate of the two enantiomers detected 'in vitro' could lead to real 'in vivo' effects.

\section{Acknowledgements}

The authors are very thankful AICTE, New Delhi for sanctioning the National Facilities in Engineering and Technology with Industrial Collaboration (File No 8023/RID/BOIII- NAFETIC-06/2005-06) project worth Rs. 20 lakhs for carrying out the research in chiral area and one of the authors (S. JaganMohan) is especially thankful to AICTE for providing the National Doctoral Fellowship.

\section{References}

1. Cayen MN (1991) Racemic mixtures and single stereoisomers: Industrial concerns and issues in drug development. Chirality 3: 94-98.

2. Rouhi AM (2002) Chiral roundup. Chem Eng News 80: 43-50.

3. Shah RR, Midgley JM, Branch SK (1998) Stereochemical origin of some clinically significant drug safety concerns: lessons for future drug development. Adverse Drug React Toxicol Rev 17: 145-190.

4. Zhang XP, Loke KE, Mital S, Chahwala S, Hintze TH (2002) Paradoxical release of nitric oxide by an L-type calcium channel antagonist, the R+ enantiomer of amlodipine. J Cardiovasc Pharmacol 39: 208-214.

5. Eichelbaum M, Gross AS (1996) Stereochemical aspects of drug action and disposition. Advances in Drug Research 28: 1-64.

6. Nation RL (1994) Chirality in new drug development-Clinical pharmacokinetic considerations. Clin Pharmacokinet 27: 249-255.

7. Tucker G (2000) Chiral switches. Lancet 35: 1085-1087.

8. Agranat I, Caner H, Caldwell (2002) Putting chirality to work: the strategy of chiral switches. Nat Rev Drug Discov 10: 753-768.

9. Indra KR (2004) Chirality in Drug Design and Development, Marcel Dekker, New York 2: 43- 52.

10. De Camp WH (1989) The FDA perspective on the development of stereoisomers. Chirality 1: 2-6.

11. Hutt AJ (1991) Drug chirality: impact on pharmaceutical regulation. Chirality 3: $161-164$.

12. Vineet B, Mayank B, Sharma PK (2010) Formulation and Evaluation of Fast Dissolving Tablets of Amlodipine Besylate Using Different Super Disintegrants and Camphor as Sublimating Agent American-Eurasian Journal of Scientific Research 5: 264-269. 